\title{
Influence of Stimulation of the Nasal Mucous Membrane with Ammonia upon the Adrenaline Secretion from the Suprarenal Gland in Non-anesthetized Dogs*
}

By

\author{
Tatsuzi Suzuki, Toshikazu Takagaki, Tsuyoshi Aoki and \\ （鍮木 達二）（高垣敏一）（青木 侹） \\ Kahei Tamabuti \\ （王淵 嘉 本）
}

(From the Physiological Laboratory of Prof. M. Wada, Tohoku University, Sendai)

(Received for publication, August 30, 1951)

That the cardio-vascular reflex is evoked by the stimulation of the nasal mucous membrane is well known; nevertheless the question whether the adrenaline secretion from the suprarenal gland is concomitantly influenced by the same sort of stimulus has not been satisfactorily decided at the present time. All of the previous investigators dealing with this question used the indirect methods for determining the adrenaline secretion.

Cordier, Magne and Mayer ${ }^{11}$ found in rabbits that the pupil, of which the sympathetic innervation was deprived of by removing the upper cervical ganglion and the pupillo-constrictor fibers were paralysed by instilling some drops of $1 \%$ atropine solution, responded to the stimulation of the mucous membrane of the upper respiratory tract with a remarkable dilation. This reflex dilation of the pupil was not observed after section of the splanchnic nerves on both sides. From this they inferred that the dilation of the denervated pupil might be due to the augmented adrenaline secretion elicited by the stimulation of the mucous membrane of the upper respiratory tract.

In studying the paradoxical pupil reaction in cats caused by various agencies, Itikawa ${ }^{2}$ in our laboratory observed that the dilation of the pupil, denervated by previous removal of the superior cervical ganglion and ciliary ganglion, was elicited by pouring of ammonia solution into the nasal cavity. However in cats, deprived bilaterally of the both suprarenal medulla or of the splanchnic nerves, the dilation of denervated

* Reported at the XXV Annual Meeting of the Japanese Physiological Society at Niigata, 1948, May. 
pupil was still causable by the irritation of the nasal mucous membrane with ammonia, though in a small degree.

Using the method of suprareno-jugular anastomosis, Tournade, Chevillot and Chardons) ascertained the augmented adrenaline secretion by the application of the same sort of stimulus. The stimulation of the mucous membrane of the nasal and laryngeal cavity of a donor dog with ammonia caused rise in the blood pressure of a recipient dog.

In the present investigation we have used non-anesthetized dogs and studied the influence of the stimulation of the nasal mucous membrane with ammonia upon the secretion of adrenaline from the suparenal medulla with simultaneous recording the arterial blood pressure.

\section{Method}

The experiments were carried out on dogs, in which the dorsal spinal roots $\left(D_{11}-L_{3}\right)$ were severed previously on both sides.

By using the method of Satake et al..$^{4)}$ the suprarenal vein blood was sampled through the lumbar way without anesthesia and laparotomy. Adrenaline in the blood samples was estimated by means of the rabbit intestine segment method. The blood pressure was recorded from the femoral artery by a $\mathrm{Hg}$ manometer.

The stimulation of the nasal mucous membrane with ammonia was performed by covering the nose of the dog during a half to one minute with the folded gauze, which was soaked with ammonia solution.

\section{Results}

Four experiments were performed with three dogs. The results are presented in the table.

\section{TABLE I}

Adrenaline Secretion and Blood Pressure after Application of Ammonia to the Nasal Mucous Membrane

\begin{tabular}{|c|c|c|c|c|c|c|c|c|c|}
\hline 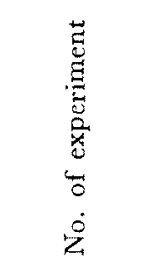 & 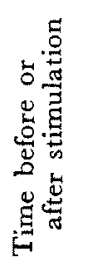 & 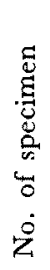 & 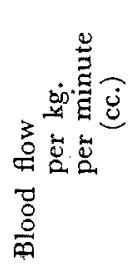 & 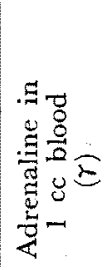 & 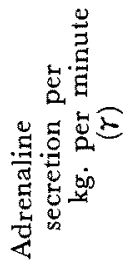 & 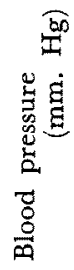 & 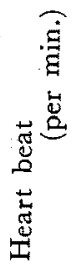 & 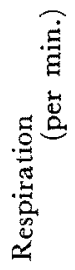 & 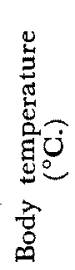 \\
\hline $\begin{array}{c}\text { Exp. 1 } \\
27 . \text { XI. ' } 47\end{array}$ & \multicolumn{9}{|c|}{ (23. X. '47. $14.9 \mathrm{~kg} . \quad \mathrm{D}_{11}-\mathrm{L}_{3}$ dorsal spinal roots sectioned.) } \\
\hline $\begin{array}{c}\text { Dog A } \hat{o} \\
15.0 \mathrm{~kg} .\end{array}$ & & $\begin{array}{l}1 \\
2\end{array}$ & $\begin{array}{l}0.28 \\
0.27\end{array}$ & $\begin{array}{l}0.05 \\
0.05\end{array}$ & $\begin{array}{l}0.01 \\
0.01\end{array}$ & 89 & 138 & 27 & 38.6 \\
\hline
\end{tabular}


Exp. 2 27. XII. ' 47

$\operatorname{Dog} \mathrm{B}$ 우 $8.5 \mathrm{~kg}$.

\section{Exp. 3}

9. IV. ' 48 Dog A 8 $12.6 \mathrm{~kg}$.

Exp. 4 20. X. ' 48 Dog $\mathrm{C}$ 우 $16.1 \mathrm{~kg}$.

Application of ammonia to the nasal mucous membrane for 30 seconds \begin{tabular}{r|r|}
$0^{\prime \prime}-30^{\prime \prime}$ & 3 \\
$30^{\prime \prime}-60^{\prime \prime}$ & 4 \\
$60^{\prime \prime}-90^{\prime \prime}$ & 5 \\
$2^{\prime}$ & \\
$44^{\prime}$ &
\end{tabular}

\begin{tabular}{l|l|}
0.17 & 0.4 \\
0.17 & 0.1 \\
0.19 & 0.075 \\
&
\end{tabular}

\begin{tabular}{l|c|c|}
0.07 & $88-78-159-146$ & 120 \\
0.02 & $146-120$ & 106 \\
0.02 & $120-105$ & 116 \\
102 & 112
\end{tabular}

$0-24$
15
15
18

38.7

(5. XII. '47. $9.7 \mathrm{~kg} . \quad D_{11}-\mathrm{L}_{3}$ dorsal spinal roots sectioned.)

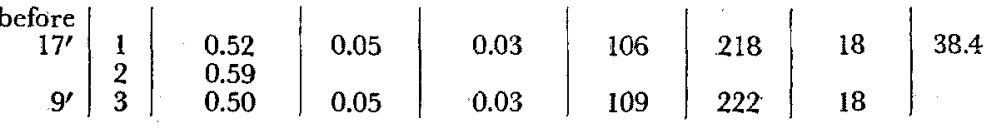

- Application of ammonia to the nasal mucous membrane for 30 seconds \begin{tabular}{r|r|}
$0^{\prime \prime}-30^{\prime \prime}$ & 4 \\
$30^{\prime \prime}-60^{\prime \prime}$ & 5 \\
$60^{\prime \prime}-90^{\prime \prime}$ & 6 \\
$90^{\prime \prime}-120^{\prime \prime}$ & 7 \\
$10^{\prime}$ & 8 \\
$15^{\prime}$ & 9
\end{tabular}

\begin{tabular}{l|l|}
0.26 & 2.4 \\
0.78 & 0.6 \\
0.38 & 0.2 \\
0.61 & 0.05 \\
0.50 & 0.05 \\
0.42 &
\end{tabular}

\begin{tabular}{l|c|c|}
0.62 & $119-136-220-30$ \\
$91-108$ & $40-180$ \\
0.47 & $108-138$ & 180 \\
0.08 & 135 & 180 \\
0.03 & 128 & 210 \\
0.03 & 117 & \\
& 109 & 204
\end{tabular}

(23. $\mathrm{X}$. '47. $14.9 \mathrm{~kg} . \quad \mathrm{D}_{11}-\mathrm{L}_{3}$ dorsal spinal roots sectioned.)
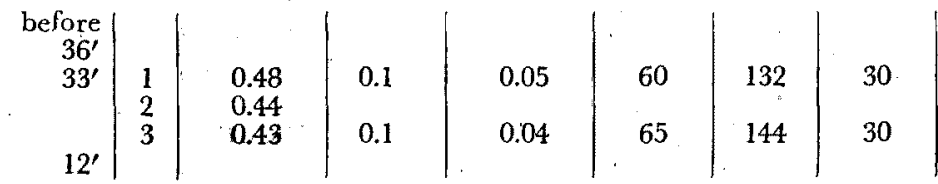

Application of ammonia to the nasal mucous membrane for 60 seconds

\begin{tabular}{r|c|c|c|c|c|c|c|c} 
after & & & & & $84-156-\mid$ & & & \\
$0^{\prime \prime}-30^{\prime \prime}$ & 4 & 0.29 & 0.4 & 0.12 & 120 & 110 & \\
$30^{\prime \prime}-60^{\prime \prime}$ & 5 & 0.35 & 0.4 & 0.14 & $120-107$ & 102 & \\
$60^{\prime \prime}-90^{\prime \prime}$ & 6 & 0.41 & 0.2 & 0.08 & 108 & 126 & 18 & \\
$90^{\prime \prime}-120^{\prime \prime}$ & 7 & 0.43 & 0.1 & 0.04 & 100 & 150 & 16 & \\
$120^{\prime \prime}-150^{\prime \prime}$ & 8 & 0.52 & 0.1 & 0.05 & 96 & 150 & 12 & 39.2 \\
$10^{\prime}$ & & & & & & & \\
$12^{\prime}$ & 9 & 0.52 & 0.1 & 0.05 & 88 & 144 & 20 &
\end{tabular}

(17. IX. '48. $16.5 \mathrm{~kg} . \quad \mathrm{D}_{11}-\mathrm{L}_{3}$ dorsal spinal roots sectioned.)

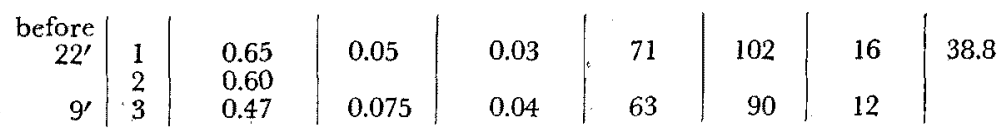

Application of ammonia to the nasal mucous membrane for 30 seconds

\begin{tabular}{r|c|c|c|c|r|r|r|r} 
after & & & & & & & & \\
$0^{\prime \prime}-30^{\prime \prime}$ & 4 & 0.29 & 0.05 & 0.02 & $81-175$ & $120-136$ & & \\
$30^{\prime \prime}-60^{\prime \prime}$ & 5 & 0.44 & 0.05 & 0.02 & $175-118$ & 130 & 24 \\
$60^{\prime \prime}-90^{\prime \prime}$ & 6 & 0.32 & 0.05 & 0.02 & $118-110$ & 132 & 20 & \\
$14^{\prime}$ & 7 & 0.48 & 0.05 & 0.02 & 75 & 102 & 15 & 38.8
\end{tabular}

The symptoms developed were almost the same in all dogs. Immediately after the covering of nose with the gauze wetted by ammonia the respiration stopped promptly. The dog twisted his body. Some seconds thereafter vigorous respiratory movements commenced. In some 
cases, the urination and repeated regurgitations were observed.

Soon after the start of the stimulation, the blood pressure rose abruptly in Dog A and in Dog C.

In Exp. $1(\operatorname{Dog} A)$, the blood pressure descended at first from 88 $\mathrm{mm}$. $\mathrm{Hg}$ to $78 \mathrm{~mm} . \mathrm{Hg}$, then it elevated and $159 \mathrm{~mm}$. $\mathrm{Hg}$ was reached about twenty seconds after the start of stimulation and afterwards it fell slowly. In Exp. 3 (Dog A), the blood pressure rose from $84 \mathrm{~mm}$. $\mathrm{Hg}$ and reached $156 \mathrm{~mm}$. Hg about twenty seconds after the start of stimulation and afterward it fell gradually. Therefore the magnitude of the blood pressure elevation in Exp. 3 was just the same as in Exp. 1.

Almost the same fluctuation of blood pressure was observed in Exp. 4 (Dog C). The blood pressure rose from $81 \mathrm{~mm}$. Hg after the stimulation and reached $175 \mathrm{~mm}$. Hg about 30 seconds after the start, then it descended gradually. In spite of this remarkable fluctuation of blood pressure, no appreciable change of heart rate was found in Exps. 1, 3 and 4.

Quite different features concerning the heart rate were observed in Exp. 2. Soon after the start of stimulation, a remarkable retardation of heart beat was observed. The initial rate of 220 beats per minute was reduced to 30 beats and it recovered again to 180 beats about 1 minute after the start of stimulation. The blood pressure rose transitorily at first from $119 \mathrm{~mm}$. $\mathrm{Hg}$ to $136 \mathrm{~mm}$. $\mathrm{Hg}$ and then it fell concomitantly with the retardation of heart beat. $91 \mathrm{~mm} . \mathrm{Hg}$ was reached about twenty seconds after the start of stimulation, then it rose gradually, reached 130 $\mathrm{mm}$. Hg about one minute after the stimulation and thereafter it descended very slowly. Therefore the change of blood pressure in this case was not so remarkable as in Dog A and Dog C.

As regards the adrenaline secretion rate, its augmentation was observed in Exp. 1 only in the first thirty-second period after the start of stimulation. It increased from $0.01 \gamma$ per $\mathrm{kg}$. per minute to $0.07 \gamma$. In the next thirty-second period the adrenaline secretion rate resumed almost its initial rate. Similar result was derived from Exp. 3, which was performed on the same $\operatorname{dog}$ as in Exp. 1. In this case, $0.04 \gamma-0.05 \gamma$ per $\mathrm{kg}$. per minute was the initial rate and $0.12 \gamma, 0.14 \gamma$, and $0.08 \gamma$ per $\mathrm{kg}$. per minite were measured in the first, the second and the third thirty-second periods respectively. In the next thirty-second period it returned to the initial rate. In this experiment the stimulation continued for one minute and in Exp. 1 for thirty seconds. The augmentation of adrenaline secretion in Exp. 3 continued somewhat longer than in Exp. 1.

In Exp. 4 the adrenaline secretion rate remained unaltered in spite of the remarkable elevation of blood pressure. In this case $0.03-0.04 \gamma$ per $\mathrm{kg}$. per minute was the original secretion rate and after stimulation it was $0.02 \gamma$. 
Contrary to the results of Exps. 1, 3 and 4, an enormously augmented adrenaline secretion was observed in Exp. 2. In this case the initial rate of adrenaline secretion was $0.03 \gamma$ per $\mathrm{kg}$. per minute. The samples obtained in the first, the second and the third thirty-second periods after application of ammonia showed the augmented adrenaline secretion such as $0.62 \gamma, 0.47 \gamma$ and $0.08 \gamma$ per kg. per minute respectively. Thereafter it returned to the initial value.

\section{SUMMARY}

Influence of stimulation of the nasal mucous membrane with ammonia upon the rate of adrenaline secretion was studied on non-anesthetized dogs, according to the lumber route method of Satake et al. The adrenaline content in the suprarenal vein blood determined by means of the rabbit intestine segment method.

In some cases, in which the blood pressure elevated abruptly after the stimulation of the nasal mucous membrane without any material alteration in the heart rate, the adrenaline secretion augmented slightly or remained unaltered.

In one case, in which the fluctuation of the blood pressure was not so remarkable, but the heart rate decreased markedly after the stimulation, an enormously augmented adrenaline secretion such as $0.6 \gamma$ per kg. per minute from one gland was observed.

We should like to express our thanks to Prof. M. Wada for his helpful advice.

\section{References}

1) Cordier, D., Magne, H. and Mayer, A., Ann. Physiol., 1927, 3, 774.

2) Itikawa, K., Tohoku J. Exp. Med., 1936, 28, 1.

3) Tournade, A., Chevillot, M. and Chardon, G., C. r. Soc. Biol., 1938, 128, 165.

4) Satake, Y., Sugawara, T. and Watanabe, M., Tohoku J. Exp. Med., 1927, 8, 501. 